\title{
DETERMINATION OF PLASMA PHENYLALANINE CONCENTRATION BY TWO DIMENSIONALTHIN LAYER CHROMATOGRAPHY AND HIGH PERFORMANCE LIQUID CHROMATOGRAPHY IN RELATION WITH DIAGNOSIS OF PHENYLKETONURIA
}

\author{
CIPRIAN-VALENTIN MIHAL ${ }^{a, b}$, CĂLIN FLAVIU LADAȘIU CIOLACUa, \\ LUCIAN FRENȚESCU $U^{c, d}$, CONSTANTIN-MARIAN PETRESCU, \\ IULIA MÂNDRUȚIU ${ }^{c}$, DORIN BECHET' ${ }^{c}$, TIBERIU NISTOR ${ }^{\mathrm{e}}$,

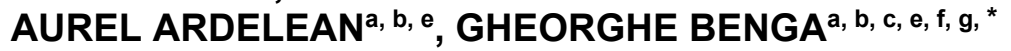

\begin{abstract}
Phenylketonuria (PKU) is a genetic disorder which can lead to serious long-term complications in children, including intellectual impairment. The cerebral damage can be largely eliminated if hyperphenilalaninemia (HPA) and PKU is detected by newborn screening and the dietary treatment (started no later than 10 days after birth), brings within 15 days the blood Phe level in the ranges $2-6 \mathrm{mg} / \mathrm{dL}$ (or equivalently $120-360 \mu \mathrm{mol} / \mathrm{L}$ ). Consequently, the measurement of plasma Phe level in children with PKU is of utmost importance. We present here in detail two methods for determination of plasma Phe concentrations in children with HPA (detected by newborn screening) or suspected to have PKU based on clinical symptoms. The first method, involving two-dimensional thin-layer chromatography (2D - TLC) on micro scale chromatograms, allows the identification of patients with PKU. However, the quantitation of plasma Phe concentration by the 2D - TLC video-densitometric method is only semiquantitative, because is accompanied
\end{abstract}

a Institute of Life Sciences, "Vasile Goldiş" Western University, 91-93 Liviu Rebreanu Street, Arad, RO-310414, Romania.

b Discipline of Cell and Molecular Biology, Faculty of Medicine, "Vasile Goldiş" Western University, 94-96 Revolutiei Boulevard, Arad, RO-310035, Romania.

c Cluj County Clinical Emergency Hospital, Laboratory of Genetic Explorations, 6 Pasteur Street, Cluj-Napoca, RO-400349, Romania.

d Department of Biochemistry, "luliu Hațieganu" University of Medicine and Pharmacy, 6 Pasteur Street, Cluj-Napoca, RO-400349, Romania.

e Cluj-Napoca Branch, Academy of Medical Sciences of Romania.

f Cluj-Napoca Branch, Romanian Academy, 9 Republicii Street, Cluj-Napoca, RO-40015, Romania.

g The Gheorghe Benga Foundation, Cluj-Napoca, Romania.

* Corresponding author: gbgbenga@gmail.com 
by large errors. In contrast, the high performance liquid chromatography determination of the plasma Phe level is fast, very sensitive and higly accurate. Both methods are rather cheap and reliable, suitable for use in countries that cannot afford more expensive procedures for diagnosis and monitoring of PKU.

Keywords: amino acids (AA), phenylalanine (Phe), phenylketonuria (PKU), hyperphenylalaninemia (HPA), high performance liquid chromatography $(H P L C)$, thin layer chromatography (TLC), phenylalanine hydroxylase (PAH).

\section{INTRODUCTION}

Phenylketonuria (PKU, OMIM 261600) and its milder variant hyperphenylalaninemia (HPA) are genetic disorders belonging to a rare group of inborn errors of metabolism which can lead to serious long-term complications in newborns, including intellectual impairment. PKU and HPA are caused by a deficiency in phenylalanine hydroxylase (PAH) enzyme (EC 1.14.16.1), that is required to metabolise the essential amino acid phenylalanine (Phe) to tyrosine (Tyr) [1 - 3]. The decreased activity of PAH (caused in most forms of PKU and HPA by mutations in the $P A H$ gene on chromosome 12q23.2.) results in intolerance to the dietary intake of Phe, and consequently, abnormally high levels of Phe and its metabolites (including phenylacetate, phenylpyruvate and phenethylamine) in the blood occur. These are toxic to the brain [1-5]. Moreover, decreased or absent activity of PAH can lead to a deficiency of Tyr and its downstream products, including melanin, I-thyroxine and the catecholamine neurotransmitters [2]. Clinically, untreated PKU is manifested by growth failure, global developmental delay, severe intellectual impairment, learning disabilities, microcephaly, seizures, EEG abnormalities, motor disturbances, marked hyperactivity with purposeless movements, aberrant behaviour, autism, psychiatric symptoms, deficits in executive function (a broad term including planning, problem solving, information processing, sustained attentions), decreased verbal memory, verbal fluency, mood, social and emotional difficulties, vision loss, skin hypopigmentation, eczematous rash, a "mousy" or "musty" odor of the breath, skin and urine (due to phenylacetate, a carboxylic acid produced by the oxidation of phenylketone) [1 - 7]. PKU has a particular significance and importance from several points of view. It was discovered in 1934 by Asbjørn Følling 
[8], one of the first Norwegian physicians to apply chemical methods to the study of medicine $[9,10]$. Its discovery established a link between metabolic disease and intellectual impairment [1-6]. The subsequent studies led to the development of programs for newborn screening (NBS) of PKU across the globe [11 - 14] and of effective dietary treatment: low-protein foods, low-Phe diet, combined with Phe-free Lamino acid supplements. When diagnosed by NBS and treated immediately, patients essentially develop normally [15 - 19]. However, neuropsychological deficits, behavioural and social issues can occur [1 7, 17 - 19]. Some patients with PKU respond to tetrahydrobiopterin (BH4), a naturally occurring essential cofactor for $\mathrm{PAH}$, which decreases blood Phe concentration and increases dietary Phe tolerance [17, 20]. $\mathrm{PAH}$ deficiency produces a spectrum of disorders, classified on the basis of blood Phe concentrations into classic PKU (Phe $>20 \mathrm{mg} / \mathrm{dL}$ or equivalently $1200 \mu \mathrm{mol} / \mathrm{L}$ ), mild PKU (Phe $=10-20 \mathrm{mg} / \mathrm{dL}$ or $600-1200$ $\mu \mathrm{mol} / \mathrm{L}$ ) and mild HPA (Phe $=2-10 \mathrm{mg} / \mathrm{dL}$ or $120-600 \mu \mathrm{mol} / \mathrm{L}$ ) [7]. The normal range of blood Phe concentrations is $0.83-1.83 \mathrm{mg} / \mathrm{dL}$ or 50 $110 \mu \mathrm{mol} / \mathrm{L}[4]$.

The classic PKU is the most common and the most severe disorder due to PAH deficiency. The cerebral damage can be largely eliminated if PKU is detected and the dietary treatment is started as soon as possible after birth: no later than 10 days, preferably in the first week of life with a goal of having within 15 days the blood Phe level within the ranges $2-6 \mathrm{mg} / \mathrm{dL}$ (or equivalently $120-360 \mu \mathrm{mol} / \mathrm{L}$ ) [6]. The treatment should be continued up to the age of 12 years maintaining the blood Phe level within these ranges. Patients with untreated Phe levels more than 10 $\mathrm{mg} / \mathrm{dL}$ (or equivalently $600 \mu \mathrm{mol} / \mathrm{L}$ ) should be treated for life, maintaining the blood Phe level within the ranges 2 - $6 \mathrm{mg} / \mathrm{dL}$ [5 - 7]. Other authors recommend the following Phe treatment ranges: birth to 8 years, Phe 1.7 $5.9 \mathrm{mg} / \mathrm{dL}$ (or equivalently 100-350 $\mu \mathrm{mol} / \mathrm{L}$ ); older children and adults, Phe $<11 \mathrm{mg} / \mathrm{dL}$ (or equivalently $<700 \mu \mathrm{mol} / \mathrm{L}$ ) [10]. Mild PKU and mild HPA are associated with lower risk of impaired cognitive development in the absence of treatment. However, regular monitoring of plasma Phe level is necessary in all subjects with PAH deficiency to control that plasma Phe level is actually within the aforementioned ranges.

A particularly special attention should be given to women with $\mathrm{PAH}$ deficiency considering pregnancy, since highly elevated concentrations of Phe are teratogenic and are a cause of increased risk of miscarriage. Specifically, the foetus can be affected by HPA which induce intrauterine developmental delay, growth retardation, facial dysmorphism, microcephaly, 
congenital heart disease. A preconception diet is required (to maintain a blood Phe target interval of $2-6 \mathrm{mg} / \mathrm{dL}$ or equivalently $120-360 \mu \mathrm{mol} / \mathrm{L}$ ) and weekly monitoring of blood Phe levels has to be performed [6].

NBS debuted as a public health program in the USA in the early 1960 's and has expanded to countries around the world in the 1970's. PKU was the first disorder diagnosed, based on detection of the presence of HPA on a blood spot obtained from a heel prick, typically performed 27 days after birth. Infants with PKU are normal at birth, the disease is not detectable by physical examination of the newborn, because the mother's body (if she does not have PKU) is able to break down Phe during pregnancy. The test can reveal elevated Phe levels after one or two days of normal infant feeding. NBS is performed to detect the disease and initiate treatment before any damage is done [1 - 7, 17 - 19]. Every 4 week delay in starting treatment results in a decline of $\sim$ four inteligence quotient (IQ) points in patients with PKU [21]. The major neurologic consequences of HPA have been largely eradicated in developed (high-income) countries because the screening for PKU is performed in all newborn children, the plasma Phe level is measured in all children with HPA and the treatment is introduced in the first days of life, no later than 10 days of life [5 - 7].

A positive result in the NBS may be due to laboratory errors, to maternal PKU, to a transient HPA due to a non-PKU disease (e.g. transient $4 \alpha$-carbinolamine dehydratase deficiency) or identifies an infant with HPA (PKU). Diagnosis of persistent HPA (PKU) is made on the basis of an elevated blood Phe concentration on the second blood sample, analysed by a referral laboratory. The upper reference limit for Phe in whole blood or plasma in newborns is $<2.5 \mathrm{mg} / \mathrm{dL}$ (or equivalent $150 \mu \mathrm{mol} / \mathrm{L}$ ). Over $98 \%$ of the children with persistent HPA, have the disorder because of mutations at the PAH locus [1, 2].

If the steps outlined above cannot be properly performed and children who present some of the aforementioned clinical symptoms are consulted by family physicians, child neurologists or pediatricians, PKU may be suspected. Consequently, in addition to the NBS there is a "clinical screening" of PKU performed by such physicians. The blood Phe concentration of such children should be measured in well equipped (referral laboratories). The upper reference limit for plasma Phe level in these children is $<2 \mathrm{mg} / \mathrm{dL}$ (or equivalently $120 \mu \mathrm{mol} / \mathrm{L}$ ) [2].

PKU screening and management practices vary widely throughout individual countries and regions; large parts of the world fall behind even the basic standards. In many less developed (low- and middle-income) 
countries PKU is either not diagnosed at birth, or it is not diagnosed at all, or it is diagnosed after the irreversible mental retardation is already installed. The reasons for these unfortunate situations are multiple: the lack of the robust infrastructure in which blood is taken from all newborn babies in the first days of life, the lack (or poor management) of well equiped laboratories that can manage and assess bloodspots efficiently, and of referral laboratories where the correct determination of blood Phe level of all infants detected to have HPA should be performed [6]. The recent Key European guidelines for the diagnosis and management of PKU [6] recommend specialized metabolic centres to be set-up for treatment and follow-up of patients.

Worldwide the incidence of PKU is approximately $1: 15,000$ to $1: 20,000$ and varies among ethnic groups, countries and geographic regions [1 - 6, 14, 22]. It is highest amongst Caucasians, between $1: 10,000$ and $1: 15,000$ people. Turkey has the highest documented incidence in the world, with 1:2,600 births (explained by the high prevalence of consanguinity), while Finland and Japan have extremely low rates with fewer than 1: 100,000 births (explained by a pronounced negative founder effect in Finland and a genetic drift in the founding of the Japanese island population) [2]. The lowest incidence of PKU was found in Thailand, <1:220,000, while a study from Slovakia reported a Roma population with an extremely high incidence (1:40 births) due to extensive inbreeding [22]. Among European countries, the incidence in Ireland and Western Scotland is 1:4,500 (among the highest in the world), while in England is $1: 14,000$. In other countries very different ranges were reported: Sweden $1: 18,000$ to $1: 14,000$, Norway $1: 14,500$, Denmark $1: 12,000$, Estonia 1:8.000, Netherlands 1:18,000, Germany 1:10,000, Poland 1: 8,000, Czechoslovakia 1:7,000, Romania 1:10,000 Republic of Moldova 1:9,000, Portugal 1:12,000, Spain 1: 20,000, France 1:13,500, Italy $1: 17,000$, Hungary $1: 11,000$, Canada $1: 20,000$, China $1: 12,000$ 1:18,000, India 1:18,000, Korea 1: 41,000, Australia 1:10,000. In the USA, the PKU incidence is from 1:10,000 to 1:25,000. In Latin American countries (a region confirmed by 20 countries), neonatal PKU incidence was assessed on a very wide range between 1:12,000 in Brazil, 1: 53,000 in Cuba to 1:160,000 in Mexico.

Romania started the national program for NBS of PKU in 1999, however probably $10 \%$ of newborns are not screened [13]. The same percentage was reported for Bulgaria and, recently, for China [23], while many countries, perhaps all African countries [24, 25], do not perform NBS. Considering the incidence of PKU in various countries, a very high number of children in the world are not correctly treated (from birth), will 
become severely retarded, and finally will need to be all the life in the care of the family or in special institutions. In addition to the tragic consequences for the patients' families and the loss of healthy individuals who could perform valuable work for society, this implies high social costs. Consequently PKU raises major public health problems [ $1-7,26)$.

In order to diagnose and monitor PKU correctly and avoid the preventable major neurologic sequelae, considering the incidence of PKU in various countries (including those were are living the majority of people in the world), it appears that a huge number (perhaps billions) of measurements of the blood Phe concentration have to be performed. There is a great need for methods to detect PKU in countries (mainly low- and middle-income) where the organization and financing of health system do not allow the use of the most modern methodologies as in the developed (high-income) countries.

We describe here in details two chromatographic methods for measurement of plasma Phe in children, in relation with the diagnosis of PKU and HPA. The first method involves rapid high-resolution twodimensional thin-layer chromatography (2D - TLC) on micro scale chromatograms. The second method uses high performance liquid chromatography (HPLC). Both methods are rather cheap and reliable, suitable for use in countries that cannot afford the more expensive procedures for diagnosis and monitoring of PKU.

\section{RESULTS AND DISCUSSION}

Figure 1 shows 2-D - TLC chromatograms of plasma AA from two infants who were found to have HPA by newborn screening and the blood has been referred to the Laboratory of Genetic Explorations (LGE) of Cluj County Clinical Emergency Hospital for confimation of HPA. Several aspects have to be noted. On the chromatograms developed in system A, Phe is not separated from leucine and isoleucine. In system B these amino acids are obtained apart from each other. In case of one infant the spot of Phe is very pale, so that HPA (and PKU) was excluded (the control case). In case of the other infant the spot of Phe is very intense, so that HPA detected by newborn screening was confirmed; moreover, based on the intensity of Phe spot, the diagnosis of classic PKU was established. These are typical examples of the value of 2D - TLC in the diagnosis of patients with PKU among infants with HPA detected by newborn screening. 

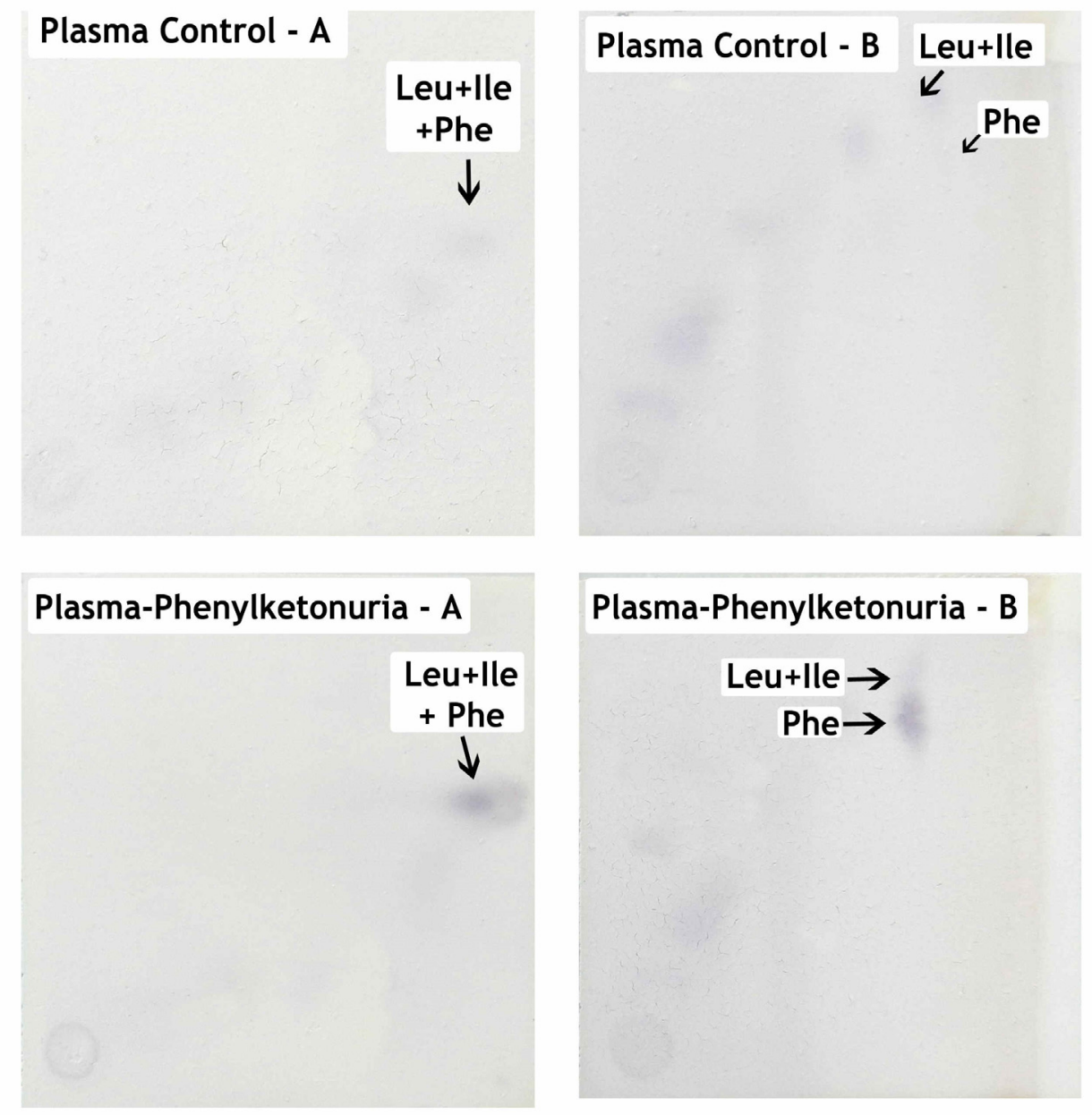

Figure 1. Aspects of 2D - TLC chromatograms of plasma amino acids from two infants who were found to have HPA by newborn screening.

In order to evaluate the possibility of quantification of Phe plasma concentration by 2D - TLC chromatography calibration curves were traced (Figures $\mathbf{2 a}$ and $\mathbf{b}$ ), based on large numbers of measurements performed with several Phe standard solutions, prepared by several operators, who also performed the estimation of Adjusted Volume on different TLC plates (as described in EXPERIMENTAL SECTION). 


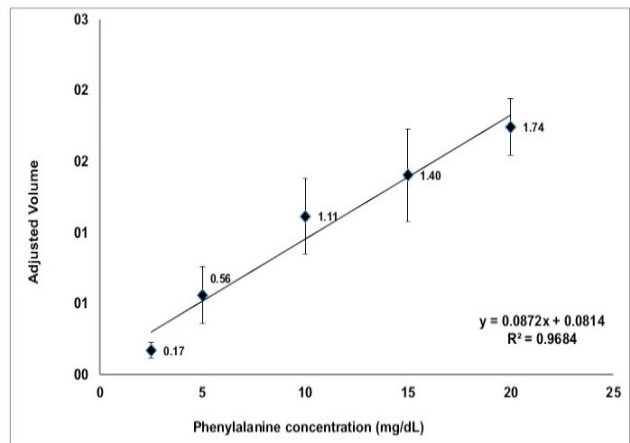

a. linear trendline

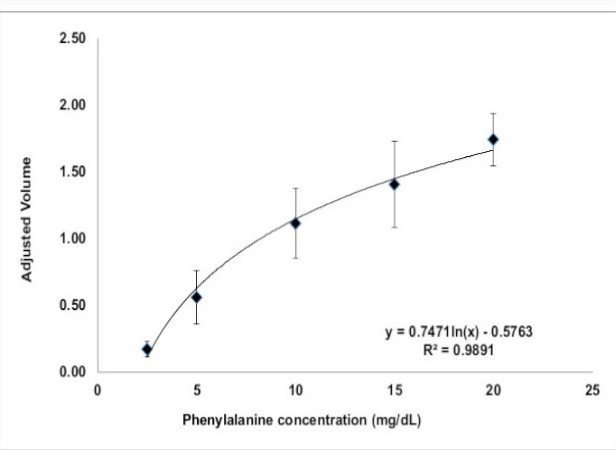

b. logarhitmic trendline

Figure 2. The standard calibration curve for measurement of Phe by quantitative 2D TLC chromatography. The parameter Adjusted Volume vs. Phe concentration ( $\mathrm{mg} / \mathrm{dL})$ is represented. The curve was obtained with Phe standard solutions having the following concentrations (in $\mathrm{mg} / \mathrm{dL}$ ): $2.5,5,10,15,20$. The means and standard deviations (SD) of 17 - 33 determinations of Adjusted Volume at each concentration of Phe standard solutions are indicated. Microsoft Excel Software was used. The linear trendline representation was chosen in a and the logarhitmic trendline representation in $\mathbf{b}$.

By comparing Figure $\mathbf{2 a}$ and $\mathbf{b}$ it appears that a logarhitmic representation is better, since the value of $R$-squared value is higher $(0.989$ vs. 0.968). However, neither the linear, nor the logarhitmic representation appears to start in the origin of the two axes. In addition, if we take into consideration the very high value of the SD at each value of Phe concentration, it appears that a precise quantification of Phe plasma concentration by 2D - TLC chromatography is not possible.

Figure 3 shows the standard calibration curve for Phe measurement by HPLC. The ranges of concentrations have been chosen to correspond from normal plasma Phe concentrations (below $2 \mathrm{mg} / \mathrm{dL}$ ) to the very high concentrations (over $20 \mathrm{mg} / \mathrm{dL}$ ), as found in the severe cases of classic PKU. The curve shows linearity from the lowest concentration (0.48 $\mathrm{mg} / \mathrm{dL})$ to the highest concentration $(29.4 \mathrm{mg} / \mathrm{dL})$ of Phe and also it appears to start in the origin of the two axes. Considering also the very small values of the SD at each concentration of Phe, it appears that the procedure described here for the measurement of Phe by HPLC is very accurate. The value of $R$-squared value is the highest possible (1.000). 


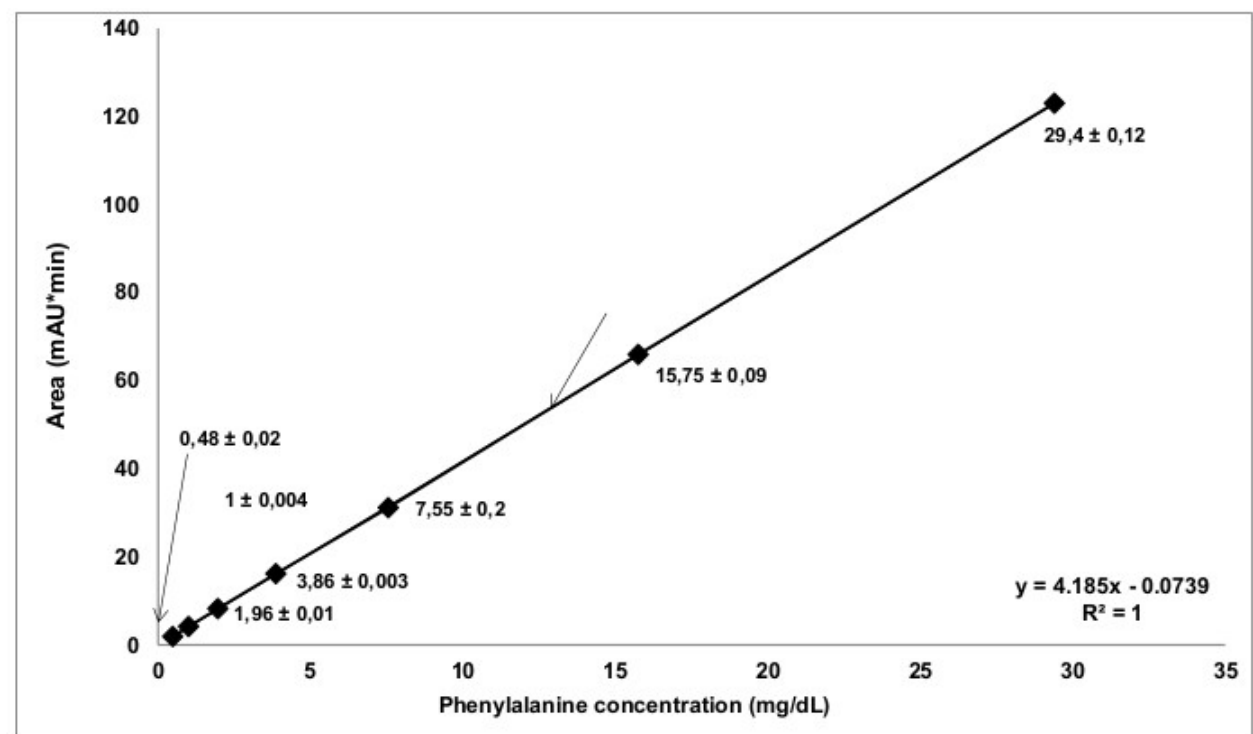

Figure 3. Graph showing the calibration curve of Phe by HPLC. Phe peak area given arbitrary absorption units (mAU) multiplied by time $(\mathrm{min})$ for seven concentrations of Phe standard solution (means and SD) are indicated. Microsoft Excel Software was used.

The methods presented here are based by the long-term experience of our group. The corresponding author has decades-long expertize in quantitative analyses of amino acids, first by paper chromatography [27 - 29], later by amino acid analyzers [30 - 34] and TLC [35]. He founded in 1980 the the Laboratory of Genetic Explorations (LGE) of Cluj County Clinical Emergency Hospital, which became a referral lab, where thousands of blood samples from children suspected of PKU (detected by newborn screening or by "clinical screening", having the symptoms aforementioned) have been sent from all over Romania. Hundreds of children with PKU have been diagnosed and their treatment monitored. In recent years the valuable collaboration with the researchers from the Institute of Life Sciences of "Vasile Goldiş" Western University of Arad allowed the accurate measurements of plasma Phe level to be performed by HPLC.

The results presented here show the value of the 2D - TLC procedure for analysis of plasma amino acids described by Wadman and coworkers [36 - 38] as a powerful tool in identification of patients with PKU. Based on the intensity of the Phe spot on the chromatogram of plasma amino acids from the infants detected by newborn screening to have HPA, the diagnosis of PKU or HPA is confirmed. For a good interpretation of the 
chromatograms (the most difficult phase of the analysis) it is necessary to have a good separations of amino acids on the chromatograms and a good experience with methodology. The decades-long use of this methodology in the lab lead by the corresponding author proved that personnel with various backgrounds working in clinical laboratories (biologists, chemists, technicians) can be trained in several weeks to perform the isolation of amino acids from blood and to identify PKU pattern.

On the other hand for quantitation of plasma Phe concentration the 2D - TLC video-densitometric methodology [39] is accompanied by large errors. The use of the logarhitmic plot and the equation of the standard curve presented in this paper may decrease the errors. However, this method is only semiquantitative.

It should be mentioned that HPLC is the most widely used quantitative screening method for diagnosing the inborn errors of metabolism (PKU included), due to its speed and specificity [40 - 52]. In addition, the measurements of blood Phe levels by HPLC did not differ statistically from the determinations of blood Phe concentrations by tandem mass spectrometry (MS/MS), the technique recognized as the "gold" standard method for its sensitivity and specificity in the diagnosis of PKU and other 30 inborn errors of metabolism [50 - 52]. HPLC is used for 40 years to measure the blood concentration of Phe and other amino acids in laboratories dedicated to diagnosis and monitoring of pacients with PKU, mainly from the developed (high-income) countries. A variety of approaches are presented, including the use of special columns, or performing pre- or post-column derivatization [40 - 50]. However, MS/MS and some HPLC methods are affordable only to the developed countries in the world $[2-7,13,19]$. It is not economic even for China [23].

The HPLC method for the determination of plasma Phe level described here requires specially trained personnel and adequate equipment, however the procedure does not involve special columns for analysis of amino acids or derivatization. Consequently, the procedure may be introduced in many clinical laboratories including those with no previous experience in diagnosis of inherited amino acid metabolic disorders.

\section{CONCLUSIONS}

Both chromatographic procedures described here may be used in laboratories from various countries, from the less developed ones (where no screening or diagnosis of PKU is performed), to countries where laboratories of genetic explorations exist, however there are not enough financial resources to measure (in all subjects who should be evaluated) the plasma Phe level by 
more expensive methodologies. The major public health problems linked to PKU not being detected, including the burden of institutionalized children with preventable mental retardation may thus be avoided.

\section{EXPERIMENTAL SECTION}

\section{Reagents and standards}

Acetonitrile (HPLC grade), Phe and most other reagents (analytical grade) were purchased from Merck (Darmstadt, Germany). Dowex-50X8, 50-100 mesh was purchased from Bio-Rad Laboratories (Richmond, CA, USA). Phe standards with concentrations indicated in Figures 2 - 4 were prepared by appropriate dilution of a stock Phe solution $(50 \mathrm{mg} / \mathrm{dL})$ in deionized water.

\section{Procedures}

Blood specimen collection, separation of plasma, isolation and concentration of amino acids

Blood from infants with HPA, detected by NBS for PKU performed in the Cluj County Clinical Emergency Hospital, were collected into heparinized Vacutainer tubes (Becton Dickinson, Basle, Switzerland) and referred within $90 \mathrm{~min}$ to the LGE within $90 \mathrm{~min}$. The samples were maintained on ice during transport. Plasma was prepared by centrifugation at $1600 \mathrm{~g}$ and at $22{ }^{\circ} \mathrm{C}$. Isolation and concentration of amino acids was performed by the "desalting" procedure developed by Wadman and coworkers [36, 37] as described previously in detail [38]. Briefly, plasma was deproteinized with trichloroaceticacid, the sample was filtered and the filtrate was passed through a column of Dowex-50X8. The column was washed with distilled water and eluted with $2 \mathrm{M}$ ammonia. After evaporation in vacuum at $40^{\circ} \mathrm{C}$, the residue was dissolved in $50 \mu \mathrm{L}$ of water. This is the concentrated solution of amino acids, free of salts and other interfering substances. An aliquot of the solution was used for the analysis of AA by 2D-TLC and another aliquot for the analysis of AA by HPLC.

Two-dimensional thin-layer chromatography of amino acids

$2 D-T L C$ was performed using the procedure of Wadman and coworkers [36, 37] with some changes [38]. TLC plates $(5 \times 5 \mathrm{~cm})$ of cellulose on glass (prepared in the lab) were used. A narrow border of cellulose $(\sim 9 \mathrm{~mm})$ is scratched off from the edge on each margin. $2 \mu \mathrm{L}$ of the concentrated solution of amino acids was applied in the lower left corner of the 
chromatogram. The spot must be kept as small as possible. The development of chromatograms was performed in small glass tanks (tightly closed with a cover) at $20^{\circ} \mathrm{C}$. The solvents must be prepared shortly before use. The first run was performed in $96 \%$ ethanol:water $(86: 14, v / v)$ until the front reached $5 \mathrm{~mm}$ from the edge of the plate. After drying in air the chromatogram was developed a second time in the same direction. After drying the chromatogram was turned at right angles and the second run was performed in $t$-butyl alcohol:methylethylketone:25\% ammonia:water $(5: 3: 1: 1, \mathrm{v} / \mathrm{v})$. The development was repeated after the chromatogram was dried. After drying at $60-80^{\circ} \mathrm{C}$ the chromatogram is stained by spraying with a solution of ninhydrin $0.42 \%$, isatin $0.01 \%$ lutidin $1 \%$ (in acetone) then dried again at $100^{\circ} \mathrm{C}$. Maximum color is obtained after $120 \mathrm{~min}$.

The final step was quantifying the level of plasma Phe by imagingdensitometric methodology applied on a Bio-Rad GS-700 imagingdensitometer (Bio-Rad Laboratories, Molecular Bioscience Group, Hercules, CA, USA), coupled to a computer. The Molecular Analyst/TM/PC Windows software for Bio-Rad's Image Analysis Systems Version 1.3 was used. The Phe spot volume (optic density $x$ spot area) and the spot volume of a similar area of background are measured on the TLC plate. Then the parameter called Adjusted Volume was calculated as the difference between the Phe spot volume and the background spot volume (as described in ref [38]). Plasma concentration was calculated by using a calibration curve for the correspondence between the Phe concentration $(\mathrm{mg} / \mathrm{dL})$ and the Adjusted Volume.

\section{HPLC analysis of amino acids}

This was performed using a Dionex Ultimate 3000 instrument (low pressure gradient pump, Dionex 3000) equipped with a Ultimate 3000 diode array detector (DAD). The analytical column used was a Thermo Scientific Acclaim 120, C18, $5 \mu \mathrm{m}$ Analytic $(4.6 \times 250 \mathrm{~mm})$ column, coupled with an Acclaim C18 guard column. The working conditions were as follows: the mobile phases were acetonitrile (solution $\mathrm{A}$ ) and water at $\mathrm{pH} 6$ with formic acid (solution B), isocratic elution with $30 \%$ solvent $A$ and $70 \%$ solvent $B$, elution time 5 minutes, column temperature $30^{\circ} \mathrm{C}$, injection volume $10 \mu \mathrm{L}$, detection wavelength $210 \mathrm{~nm}$.

\section{ACKNOWLEDGEMENTS}

The corresponding author remains grateful to his former coworkers and colleagues with whom the methods of analysis of amino acids were introduced in the medical laboratories in Romania (27 - 29). He has introduced 
later the TLC methods of analyses of amino acids for the diagnosis of amino acid metabolism disturbances after a visit performed in 1982 in the Laboratory of the late Professor Syde K. Wadman of The Wilhelmina Kinderziekenhuis, Utrecht, The Netherlands. Professors Gheorghe and Ileana Benga remain deeply grateful to Professor Wadman for inviting them, for his hospitality, and for training generously offered, also to Prof. Wadman's coworkers for their kindness to teach them the methods used in their lab for performing the diagnosis of inborn errors of metabolism.

Professor Gheorghe Benga founded in 1978 and coordinated the First Laboratory of Genetic Explorations (LGE) of Cluj County Clinical Emergency Hospital, Cluj-Napoca, Romania. LGE was accredited as a unit of the research platform of The Academy of Medical Sciences of Romania, also under the Aegis of The Romanian Academy. He is grateful to his former coworkers from the Center of Molecular Medicine and Neurosciences of The "luliu Hațieganu" University of Medicine and Pharmacy Cluj-Napoca for the decades of collaboration.

The authors thank also to Verona Pascu, Veronica Ardelean, Emese Opriș, and Livia Budișan for technical help in diagnoses of amino acid metabolism disturbances over the years in the LGE. Most of the patients who were investigated in this lab were selected and referred by the Pediatric Neurology Clinic of Cluj Clinical Emergency Children Hospital, lead by the former Chief of this Clinic, Professor lleana Benga. Out of several thousands of samples referred to LGE for amino acid analyzes several hundreds of children with PKU were diagnosed and treated.

\section{REFERENCES}

1. C. L. Scriver, S. Kaufman, Hyperphenylalaninemia: phenylalanine hydroxylase deficiency. In C. Scriver, A. L. Baudet, W. S. Sly (eds) "The Metabolic and Molecular Bases of Inherited Disease", 8th ed., McGraw Hill, New York, 2001, 1667- 1724.

2. R. A. Williams, C. D. S. Mamotte, Burnett, R. John, The Clinical Biochemist, 2008, $29,31$.

3. J. J. Mitchell, Y. J. Trakadi, C. R. Scriver, Genetics in Medicine, 2011, 13,697.

4. N. Blau, F. J. van Spronsen, H. L. Levy, Lancet, 2010, 376, 1417.

5. J. Vockley, H. C. Andersen, K. V. Antschel, N. E. Braverman, B. K. Burton, D. M. Frazier, J. Mitchell, W. E. Smith, B. H. Thompson, S. A. Berry, Genetics in Medicine, 2014, 16, 188. 
6. F. J. van Spronsen, A. M. J. van Wegberg, K. Ahring, A. Bélanger-Quintana, N. Blau, A. M. Bosch, A. Burlina, J. Campistol, F. Feillet, M. Giżewska, S. C. Huijbregts, S. Kearney, V. Leuzzi, F. Maillot, A. C. Muntau, F. K. Trefz, M. van Rijn, J.H. Walter, A. MacDonald, The Lancet Diabetes \& Endocrinology, 2017, 5, 743.

7. S. A. Berry, C. Brown, M. Grant, C. L. Greene, E. Jurecki, J. Koch, K. Moseley, R. Suter, S. C. van Calcar, J. Wiles, S. Cederbaum, Genetics in Medicine, 2013, 15, 591.

8. A. Følling, Hoppe-Seylers zeitschrift für physiologische Chemie, 1934, 227,169.

9. I. Følling, Acta Pediatrlca, Suppl. 1994, 407, 4.

10.N. Blau, P. Burgard. Disorders of Phenylalanine and Tetrahydrobiopterin Metabolism. In N. Blau, J. Leonard, G. Hoffmann, J. Clarke (eds) "Physician's Guide to the Treatment and Follow-up of Metabolic Diseases", Springer Verlag, Heidelberg, 2006, 25-34.

11.R. Guthrie, A. Susi, Pediatrics, 1963,32, 338.

12.U. Groselj, M. Z. Tansek, T. Battelino, Molecular Genetics and Metabolism, 2014, 113, 8.

13.U. Groselj, M. Z. Tansek, A. Smon, N. Angelkova, D. Anton, I. Baric, M. Djordjevic, L. Grimc, M. Ivanova, A. Kadam, V. M. Kotori, H. Maksic, O. Mărginean, O. Mârgineanu, O. Milihanovic, F. Moldovanu, M. Mureşan, S. Murko, M. Nanu, B. R. Lampret, M. Samardzic, V. Sarnavkra, A. Savov, M. Stojiljkovic, B. Suzic, R. Tincheva, H. Tahirovic, A. Toromanovic, N. Uşurelu, T. Battelino. Molecular Genetics and Metabolism, 2014, 113, 42.

14.M. Giźewska, A. MacDonald, A. Bélangee-Quintana, A. Burlina, M. Cleary, T. Coskun, F. Feillet, A. C. Muntau, F. F. Trefz, F. J. van Spronsen, N. Blau, European Journal of Pediatrics, 2016, 175, 261.

15.H. Bickel, J. Gerrard, E. M. Hickmans, Lancet, 1953, 265, 812.

16.I. Ahring, A. Bélanger-Quintana, K. Dokoupil, H. Gokmen Ozel, A. M. Lammardo, A. MacDonald, K. Motzfeldt, M. Nowacka, M. Robert, M. van Rijn, Clinical Nutrition, 2009, 28, 231.

17.N. Blau, P. Burgard. Disorders of Phenylalanine and Tetrahydrobiopterin Metabolism. In N. Blau, J. Leonard, G. Hoffmann, J. Clarke (eds) "Physician's Guide to the Treatment and Follow-up of Metabolic Diseases", Springer Verlag, Heidelberg, 2006, 53 - 89.

18.N. Al Hafid, J. Christodoulou, Translational Pediatrics, 2015, 4, 304.

19.N. Blau, A. MacDonald, F. J. van Spronsen, Molecular Genetics and Metabolism, 2011, 104, S1.

20.C. O. Harding, Biologics Targets \& Therapy, 2010, 4, 231.

21.I. Smith, M. G. Beasley, A. E. Ades, Archives of Diseases in Childhood, 1990, $65,472$.

22.V. Ferák, D. Siváková, Z. Sieglová, 1987). Bratislavské Lekárske Listy (Bratislava Medical Journal). 1987, 87, 168.

23.I. Wang, H. Zou, F. Ye, X. Li, Z. Chen, J. Chen, B. Han, W. Yu, C. He, M. Shen, Journal of Inherited Metabolic Diseases, 2017, 40, 369. 
DETERMINATION OF PLASMA PHENYLALANINE CONCENTRATION BY TWO DIMENSIONALTHIN...

24.S. Khemir, M. El Asmi , H. Sanhaji, M. Feki, R. Jemaa, N. Tebib, J. L. Dhondt, M. F. Ben Dridi, A. Mebazaa, N. Kaabachi, Clinical Neurology and Neurosurgery, 2011, $113,727$.

25.E. Sladkevicius, R. J. Pollitt, A. Mgadmi, J. F. Guest, Applied Health Economics and Health Policy, 2010, 8, 407.

26.V. Belengeanu, L. Moș, A. Covaci,, Gh. Benga, Acta Endocrinologica (Buc) 2016, 12, 1.

27.A. Popesco, Gh. Benga, D. Coman, V. Pop, Revue Internationale d'Hepatologie, 1966, 16, 1419.

28.Gh. Benga, D. Coman, Spitalul, 1967, 15, 312.

29.A. Hodârnău, I. Chira, D. Coman, M. Căprioară, Clujul Medical, 1969, 42, 519.

30.Gh. Benga, W. Ferdinand, International Journal of Biochemistry, 1977, 8, 17.

31.Gh. Benga, V.I. Pop, O. Popescu, I. Benga, W. Ferdinand, Bioscience Reports, $1991,11,53$.

32.Gh. Benga, A. Hodârnău, R. Tilinca, V. Borza, W. Ferdinand, Bioscience Reports, 1991, 11, 95.

33. Gh. Benga, D. Poruţiu, A. Hodârnău, W. Ferdinand, Comparative Biochemistry and Physiology, 1992, 102 B, 123.

34.Gh. Benga, W. Ferdinand, Bioscience Reports, 1995, 15, 111.

35.I. Benga, Gh. Benga, In P. Grigorescu-Sido (ed) "The Second National Symposium of Genetic, Endocrine and Metabolic Diseases in Children, Cluj Napoca, 1998", Casa Cărţii de Ştiinţă, Cluj-Napoca, 1998, pp. 29-38.

36.S. K. Wadman, H. Fabery de Jonge, P. K. de Bree, Clinica Chimica Acta, 1969, $25,87$.

37.S. K. Wadman, H. Fabery de Jonge, P. K. de Bree, Clinica Chimica Acta, 1969, 25, 87.

38.H. J. Bremer, M. Duran, J. P. Kamerling, H. Przyrembel, S. K. Wadman, "Disturbances of Amino Acid Metabolism: Clinical Chemistry and Diagnosis", Urban \& Schwarzenberg, Baltimore - Munich, 1981: 425.

39.R. Vulturar, "Tulburări genetice în metabolismul aminoacizilor", Ph. D. Thesis, "Iuliu Hațieganu" University of Medicine and Pharmacy, Cluj-Napoca, Romania, 2004.

40.N. D. Atherton, A. Green, Clinical Chemistry, 1988, 34, 224.

41.N. D. Atherton, Clinical Chemistry, 1989, 35, 975.

42.I. Czauderna, J. Kowalczyk, Journal of Animal and Feed Sciences, 1998, 7, 453.

43.I. R. Allen, T. J. O. Degg, P. A. Rushworthl, M. Smith, M. J. Henderson, Annals of Clinical Biochemistry, 1999, 36, 207.

44.E. L. Schwarz, W. L. Roberts, M. Pasquali, 2005, 354, 83.

45.F. Haghighi, S. Talebpour, V. Amini, A. Ahmadzadeh, M. Farhadpour, Analytical Methods, 2015, 7, 7560.

46.H. Danafar, M. Hamidi, Pharmaceutical and Biomedical Research, 2015, 1, 11.

47.Y. Song, K. Takatsuki, T. Sekiguchi, T. Funatsu, S. Shoji, M. Tsunoda, 2016, Amino Acids, 48, 1731.

48.F. A. Abadi, A. Mirfazeli, H. Zaeri, M. Nejabat, M. Taherizadeh, M. Ariaie, A. Aliarab, H. Josaghani, Medical Laboratory Journal, 2016, 10, 52. 
C.-V. MIHALI, C. F. L. CIOLACU, L. FRENȚESCU, C.-M. PETRESCU, I. MÂNDRUȚIU, D. BECHET, T. NISTOR, A. ARDELEAN, G. BENGA

49. A. Abbaskhanian, D. Zamanfar, A. Parvaneh, E. Asadpoor, H. Rouhanizadeh, A. Jafarnia, M. Shokzadeh, International Journal of Preventive Medicine, 2017, 8, 93.

50. I. S. López, S. M. Santoyo, M. V. Amieva, Acta Pediátrica de México, 2012, 33, 296.

51.I. Contreras, E. Alonso, L. E. Fuentes, MEDICC Review, 2015, 17, 23.

52.A. O. Gregory, C. Yu, R. H. Singh, Genetics in Medicine, 2007, 9, 761. 